\title{
Experimental and numerical study on soot formation in laminar diffusion flames of biodiesels and methyl esters
}

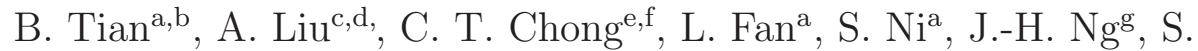 \\ Rigopoulos $^{\mathrm{d}}$, K. H. Luo ${ }^{\mathrm{c}}$, S. Hochgreb ${ }^{\mathrm{a}}$ \\ ${ }^{a}$ Department of Engineering, University of Cambridge, Trumpington Street, CB2 1PZ \\ Cambridge, United Kingdom \\ ${ }^{b}$ College of Engineering and Technology, University of Derby, Markeaton Street, DE22 \\ $3 A W$ Derby, United Kingdom \\ ${ }^{c}$ Department of Mechanical Engineering, University College London, Torrington Place, \\ London WC1E 7JE, United Kingdom \\ ${ }^{d}$ Department of Mechanical Engineering, Imperial College London, Exhibition Road, \\ London SW7 2AZ, United Kingdom \\ ${ }^{e}$ China-UK Low Carbon College, Shanghai Jiao Tong University, Lingang, Shanghai, \\ 201306, China \\ ${ }^{f}$ School of Mechanical Engineering, Faculty of Engineering, Universiti Teknologi \\ Malaysia, 81310 Skudai, Johor, Malaysia \\ ${ }^{g}$ Faculty of Engineering and Physical Sciences, University of Southampton Malaysia, \\ 79200 Iskandar Puteri, Johor, Malaysia
}

\begin{abstract}
Biodiesel and blends with petroleum diesel are promising renewable alternative fuels for engines. In the present study, the soot concentration generated from four biodiesels, two pure methyl esters, and their blends with petroleum diesel are measured in a series of fully pre-vapourised co-flow diffusion flames. The experimental measurements are conducted using planar laser induced-incandescence (LII) and laser extinction optical methods. The results show that the maximum local soot volume fractions of neat biodiesels are $24.4 \%-41.2 \%$ of pure diesel, whereas the mean soot volume fraction of
\end{abstract}

Email address: anxiong.liu@ucl.ac.uk (A. Liu) 
neat biodiesel cases was measured as $11.3 \%-21.3 \%$ of pure diesel. The addition of biodiesel to diesel not only reduces the number of inception particles, but also inhibits their surface growth. The discretised population balance modelling of a complete set of soot processes is employed to compute the $2 \mathrm{D}$ soot volume fraction and size distribution across the tested flames. The results show that the model also demonstrates a reduction of both soot volume fraction and primary particle size by adding biodiesel fuels. However, it is not possible to clearly determine which factors are responsible for the reduction from the comparison alone. Moreover, analysis of the discrepancies between numerical and experimental results for diesel and low-blending cases offers an insight for the refinement of soot formation modelling of combustion with large-molecule fuels.

Keywords: Biodiesel, Soot, Laser induced incandescence, soot model

\section{Introduction}

1 Soot is a known hazardous pollutant resulting from the combustion of 2 carbon fuels; understanding how to suppress its formation via the addition 3 of biodiesel or methyl ester (ME) surrogates is important for the development 4 of low-emission combustion techniques. Biodiesels are typically mixtures of 5 methyl esters (MEs) of long chain fatty acids, which are produced via the

6 transesterication process of triglycerides and short-chain alcohols [1]. The 7 presence of the ester moiety in the molecules of the biodiesel leads to lower 8 soot formation during its combustion compared with conventional petroleum 9 diesel [2].

10 Soot measurements have been made in a number of well-controlled lab- 
scale flames and reactors, which can act as test beds for soot propensity of biofuel blends. Tran et al. [3] investigated the sooting tendency of soybean biodiesel and petroleum diesel blends using LII in a wick-fed lamp, showing that the addition of biodiesel produced significantly lower soot [4].

Abboud et al. [5] evaluated the soot reduction effect of the addition of methyl decanoate (MD), a biodiesel surrogate to diesel in coflow diffusion flames. A similar method was used by Gao et al. [6] to investigate the chemical mechanism and soot reduction effects of dibutyl ether (DBE) in addition to MD. Kholghy et al. [7] analysed the chemical properties of the ester bond for soot evolution and morphology in the flame with a biodiesel surrogate comprising 50\%/50\% molar blend of n-decane and methyl-octanoate. Merchan-Merchan et al. [8] measured the soot volume fraction $\left(f_{v}\right)$ profiles in a pre-vapourised diffusion flame of biodiesels, and evaluated the effect of blending ratio (with diesel) and oxygen concentration in the co-flow on soot formation. The same group [9] also investigated the evolution profiles of the morphological properties of soot in pre-vaporised diffusion flames of three types of biodiesel. Lemaire et al. [10] extensively studied the soot and PAH formation in turbulent spray flame of diesel, diesel surrogate, rapeseed methyl ester (RME) and different RME surrogates, and concluded that the soot volume fraction measured in a pure RME flame was around $16 \%$ that of pure diesel. Das et al. [11] investigated the effect of the double bonds on the sooting properties of esters and produced insights regarding the strong dependence of the sooting tendencies of esters on their chemical structure and on their unsaturation degree. Chong et al. [12] compared the propensity of soot formation between diesel and waste cooking oil over both a laminar pool 
flame and a prevapourised diffusion flame. These studies have expanded the understanding of soot formation and properties in pre-vapourised diffusion flames with biodiesel and MEs. In all previous studies cited above, except for our recent study on diesels and cooking oils [13], the fuel was diluted with $\mathrm{N}_{2}[6-9,14]$ or argon [5] to improve flame stability during experiments. However, the inert carrier gas may affect the soot formation and yield in these types of flames [15].

In the present study, neat undiluted fuel vapour is delivered to the fuel tube to the burner nozzle. Due to the absence of a carrier gas, however, the overall flow velocity of the vapour in the fuel tube is kept very low $(\leq$ $0.8 \mathrm{~cm} / \mathrm{s}$ ), so as to minimise flame hydrodynamic stability. In addition, the inherent stability issue of vapour feeding rate was solved by: 1) increasing the volume of the vapour delivery tubing; 2) using a precisely controlled evaporating system. The undiluted flames provide information on the soot formation in neat biodiesel vapour flames, which can serve as important references for engine emission studies and as validation targets for modelling. Four different actual methyl ester biodiesels derived from carotino red palm $(C P)$, rice bran $(\mathrm{RB})$, duck fat $(\mathrm{DU})$, goose fat $(\mathrm{GO})$, and their blends with petroleum diesel are investigated. Diesel and two pure methyl esters are tested as references. The soot volume fraction $\left(f_{v}\right)$ in tested flames is then measured using extinction-calibrated LII [16] and corrected for signal trapping effects using the algorithm developed in [17].

Modelling of soot formation and oxidation of biomass-derived fuels is a considerable challenge due to the complexity of chemical reactions and soot formation pathways in the biodiesel fuels. The present study not only 
presents new experimental data on the behaviour soot from selected fuels, but also uses a comprehensive kinetic mechanism developed for a large variety of fuels related to diesel and biodiesel [18] to simulate the pyrolysis and combustion of fuel blends. A discretised population balance method, considering a complete set of processes of soot evolution [19], is coupled with the reacting flow to model soot formation in the combustion of biodiesel blends. The experimental setup and model details are described forthwith.

\section{Experiment}

\subsection{Fuels and flame}

The tested fuels in the present study are all methyl esters (ME) produced from plant oil or animal fat feedstocks via the transesterification process. The feedstocks used are carotino red palm oil (CP), rice bran (RB), duck fat (DU) and goose fat (GO). The two methyl esters tested are methyl laurate (ML) and methyl myristate (MM). European low-sulfur diesel which had been extensively studied on sooting tendency $[10,13,20]$ is tested as a baseline. The composition of different types of biodiesel is measured using a gas chromatograph (GC, Agilent 7620A) based on the EN14103 standard, and listed in Table 1. The measured average formula for CP, RB, DU and GO are: $\mathrm{C}_{18.7} \mathrm{H}_{36.9} \mathrm{O}_{2.0}, \mathrm{C}_{18.6} \mathrm{H}_{36.9} \mathrm{O}_{2.0}, \mathrm{C}_{18.3} \mathrm{H}_{36.5} \mathrm{O}_{2.0}$ and $\mathrm{C}_{18.5} \mathrm{H}_{36.6} \mathrm{O}_{2.0}$, respectively. The formula for ML and $\mathrm{MM}$ are $\mathrm{C}_{13} \mathrm{H}_{26} \mathrm{O}_{2}$ and $\mathrm{C}_{15} \mathrm{H}_{30} \mathrm{O}_{2}$. It should be clarified that saturated C18 or C19 methyl esters (methyl palmitate and methyl stearate, respectively) could be more suitable than C13 and C15 for a direct comparison with the tested biofuels. However, their high boiling temperature and melting points rendered these substances very difficult to 
vapourise with the current set up without further heating. For safety reasons, this was not feasible in the present study. All biodiesels tested contain about $11 \%$ (mass fraction) of oxygen. However, the unsaturation levels of the two types of animal fat derived biodiesel (DU and GO) are much lower than plant-based biodiesel ( $\mathrm{CP}$ and $\mathrm{RB}$ ), as listed on Table 1. A previous study [17] on unsaturation suggests that the soot yields of $\mathrm{CP}$ and $\mathrm{RB}$ are higher than DU and GO. In contrast, the two fully-saturated methyl esters of ML and MM are expected to produce the least soot.

A diagram of the pre-vapourised diffusion burner is shown in Fig. 1. The liquid fuels are injected into the vaporising system via a syringe pump (NE300 Just Infusion Syringe Pump, with accuracy Within $\pm 1 \%$ of the displayed value). The mass flow rates of fuels are regulated based on a previous study of the mass consumption rates of the liquid fuels in a buoyancy-induced laminar pool flame as described in $[12,17]$. The values are selected as 0.119 $\mathrm{g} / \mathrm{min}$ for diesel, $0.116 \mathrm{~g} / \mathrm{min}$ for $\mathrm{CP}, 0.104 \mathrm{~g} / \mathrm{min}$ for $\mathrm{RB}, 0.111 \mathrm{~g} / \mathrm{min}$ for DU, $0.094 \mathrm{~g} / \mathrm{min}$ for GO, $0.130 \mathrm{~g} / \mathrm{min}$ for ML and $0.115 \mathrm{~g} / \mathrm{min}$ for MM. All values above are with $\pm 1 \%$ instrumental uncertainty. Nevertheless, the estimated heat release rates for all the tested neat cases are within $\pm 15 \%$ of the mean. A co-flow of air at $0.18 \mathrm{~m} / \mathrm{s}$ is used to stabilise the diffusion flame. The fuel delivery line is heated using electrical heating tapes (OMEGA STH102 series). The temperature of the tapes is controlled by two closed-loop temperature controllers, while a thermometer is used to monitor the temperature of the heating tape at the inlet of the system, which is denoted as $T_{1}$. The temperatures in the middle and the outlet of the system are denoted as $T_{2}$ and $T_{3}$ respectively. During the tests, $T_{1}, T_{2}$ and $T_{3}$ are maintained constant 


\begin{tabular}{lllllll}
\hline & $\mathrm{CP}$ & $\mathrm{RB}$ & $\mathrm{DU}$ & $\mathrm{GO}$ & $\mathrm{ML}$ & $\mathrm{MM}$ \\
\hline $\mathrm{C} 12: 0$ & 0.000 & 0.000 & 0.000 & 0.000 & 1.000 & 0.000 \\
C14:0 & 0.003 & 0.004 & 0.009 & 0.004 & 0.000 & 1.000 \\
C16:0 & 0.139 & 0.216 & 0.317 & 0.268 & 0.000 & 0.000 \\
C18:0 & 0.602 & 0.431 & 0.565 & 0.588 & 0.000 & 0.000 \\
C18:1 & 0.172 & 0.321 & 0.110 & 0.131 & 0.000 & 0.000 \\
C18:2 & 0.068 & 0.012 & 0.000 & 0.009 & 0.000 & 0.000 \\
C18:3 & 0.016 & 0.016 & 0.000 & 0.000 & 0.000 & 0.000 \\
\hline Unsat. & 0.356 & 0.394 & 0.110 & 0.149 & 0.000 & 0.000 \\
Avg. & $\mathrm{C}$ & & & & & \\
Chain & 17.71 & 17.55 & 17.33 & 17.45 & 12.00 & 14.00 \\
$M W^{a}$ & 293.2 & 291.0 & 288.4 & 290.0 & 214.0 & 242.0 \\
$\Delta H^{b}$ & 40.6 & 37.50 & 39.4 & 39.4 & 38.02 & 39.03 \\
$Y_{C}$ & 0.77 & 0.77 & 0.76 & 0.76 & 0.73 & 0.74 \\
$Y_{H}$ & 0.13 & 0.12 & 0.13 & 0.13 & 0.12 & 0.12 \\
$Y_{O}$ & 0.11 & 0.11 & 0.11 & 0.11 & 0.15 & 0.13 \\
$X_{C}$ & 18.7 & 18.6 & 18.3 & 18.5 & 13 & 15 \\
$X_{H}$ & 36.7 & 36.3 & 36.4 & 36.6 & 26 & 30 \\
$X_{O}$ & 2 & 2 & 2 & 2 & 2 & 2 \\
\hline
\end{tabular}

a: units: $\mathrm{g} / \mathrm{mol}$; b: units: $\mathrm{MJ} / \mathrm{kg}$

Table 1: Properties and compositions of biodiesel fuels. CP: carotino red palm oil biodiesel. RB: rice bran biodiesel. GO: goose fat biodiesel. DU: duck fat biodiesel. ML: methyl laurate. MM: methyl myristate. Top section: Composition (mole fraction) of biodiesels measured using GC. C12:0 means 12 carbon atoms in the main chain of fatty acid with zero double $\mathrm{C}=\mathrm{C}$ bonds. Bottom section: Properties and elemental mass percentage of biodiesels. The degree of unsaturation is calculated by multiplying the mole fraction of each species times the associated number of $\mathrm{C}=\mathrm{C}$ double bonds. Heating values $\Delta H$ of $\mathrm{CP}$ are from $[4,21]$; heating value of yellow grease biodiesel from [4] is used as values of DU and GO; values for RB are from [22, 23]; values for ML and MM are from the NIST website $[24,25]$. The mass fractions and average molecular formula are denoted by $Y$ and $X$, respectively. 
sufficiently long residence times ( $\geq 3 \mathrm{~min}$ ) to ensure full evaporation.

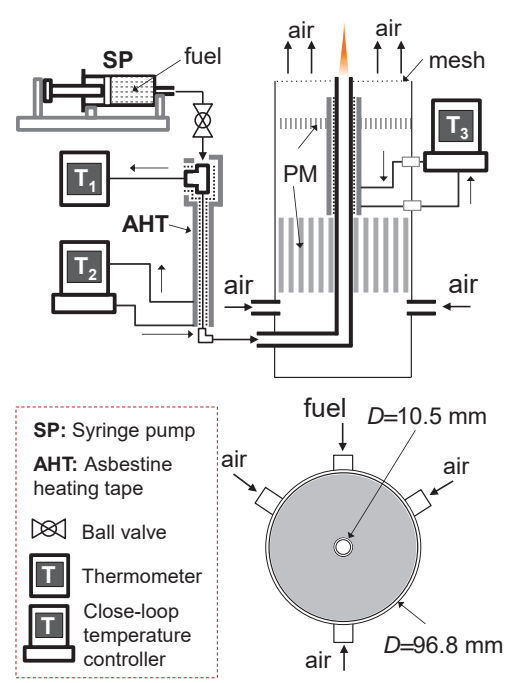

Figure 1: Schematic of the co-flow diffusion flame. point of the fuels are below $400{ }^{\circ} \mathrm{C}$ [4], the temperature is sufficiently high for a full vapourisation. The fuel vapourisation line is designed to achieve

at $520 \pm 30{ }^{\circ} \mathrm{C}, 470 \pm 30{ }^{\circ} \mathrm{C}$ and $400 \pm 30{ }^{\circ} \mathrm{C}$, respectively. As the boiling

\subsection{LII measurement and calibration}

The planar 2D LII measurements are performed using a setup similar to that in Ref. [17], in which the measured LII signal is quantitatively calibrated via absorption, with correction for signal-trapping. The full details of the optimisation, calibration and correction procedure of the signals can be found in Ref. [17].

\subsection{SEM sampling}

Soot particle samples are collected by using the thermophoretic deposition method used in [9]. The soot produced from the flames were collected 
by using a pre-cooled quartz plate at about $0{ }^{\circ} \mathrm{C}(76.2 \times 25.4 \times 1.0 \mathrm{~mm})$. By inserting the plate in the flame at the fixed HAB of $15 \mathrm{~mm}$ for approximately $2 \mathrm{~s}$, soot particles are deposited on the plate driven by the temperature gradient between the cold surface and the hot environment. The surface growth of particles can be quickly quenched, and the particles tend to freeze on the surface [9]. Previous studies using quartz plates to collect soot samples show that the collection time does not significantly influence the soot characteristics $[26,27]$. The primary soot particle size is analysed using a scanning electron micropscope (SEM) (LEO GEMINI 1530VP FEG-SEM) system. From the SEM images, the distribution of the primary particle size is determined and fitted using lognormal distributions based on the measurement of 100 random primary particles.

\section{Soot modelling}

The simulation employs a semi-detailed kinetic mechanism [18] for the pyrolysis and combustion of a large variety of gasoline and diesel fuels in premixed flames, where 249 chemical species and 8153 combined chemical reactions are considered. This mechanism was initially developed based on hierarchical modularity and then improved via the validation with a vast amount of experimental data on the laminar flame speeds of hydrocarbon and oxygenated fuels. In the mechanism, long-chain alkanes, alkenes and a small fraction of aromatic hydrocarbons represent the composition of the diesel, while saturated and non-saturated methyl esters represent the composition of biodiesel fuels. In addition, aromatic hydrocarbons are also involved in the chemical kinetics to model the nucleation process in the soot forma- 
tion. Therefore, the mechanism cited in the supplementary material in Ref. [18] is integrated to deal with the chemical reactions of diesel and biodiesel surrogates, as well as the soot formation precursors.

According to $[28,29]$, the diesel fuel is approximated as a mixture of longchain alkanes and alkenes, with a small fraction of aromatic hydrocarbons. The four biodiesel surrogates are assumed to be a mixture of a long-chain alkane (n-hexadecane, n- $\mathrm{C}_{16} \mathrm{H}_{34}$ ), a alkene (1,4-hexadiene, HXD14), a saturated methyl ester (MD) and a non-saturated methyl ester (methyl trans3-hexenoate, MH3D) [30]. However, some species are absent in the mechanism [18], and are thus substituted by other substances of similar chemical structures. Therefore, the approximate composition of the diesel fuel and four biodiesel surrogates used in the simulation is shown in Tables 2 and 3.

\begin{tabular}{lcr} 
Table 2: Setup of composition of diesel (mass \%) \\
\hline Composition & Refs. $[28,29]$ & Present \\
\hline $\mathrm{C}_{10} \mathrm{H}_{22}$ & 5.6 & 7.6 \\
$\mathrm{C}_{12} \mathrm{H}_{26}$ & 20.9 & 20.9 \\
$\mathrm{C}_{14} \mathrm{H}_{30}$ & 26.0 & 26.0 \\
$\mathrm{C}_{16} \mathrm{H}_{34}$ & 16.6 & 30.4 \\
$\mathrm{C}_{18} \mathrm{H}_{36}$ & 15.8 & - \\
$\mathrm{C}_{6} \mathrm{H}_{12}$ & 3.7 & 3.7 \\
$\mathrm{C}_{10} \mathrm{H}_{18}$ & 6.4 & 6.4 \\
$\mathrm{C}_{7} \mathrm{H}_{8}$ & 5.0 & 5.0 \\
\hline
\end{tabular}

The soot model involves the processes of nucleation by $\mathrm{PAH}$ dimerisation, surface growth by the HACA mechanism [31], PAH condensation and coagulation of spherical particles and fractal aggregates. Naphthalene (A2), phenanthrene (A3), pyrene (A4) are used to model PAH dimerisation, with sticking efficiencies $0.001,0.015,0.025$ respectively [32]. Reversibility 
Table 3: Setup of composition of biodiesel surrogates (mole \%)

\begin{tabular}{llllll}
\hline Ref. [30] & Present & CP & RB & DU & GO \\
\hline $\mathrm{MD}:$ & $\mathrm{C}_{11} \mathrm{H}_{22} \mathrm{O}_{2}$ & 53.09 & 54.98 & 52.99 & 52.84 \\
$\mathrm{C}_{11} \mathrm{H}_{22} \mathrm{O}_{2}$ & & & & & \\
\hline $\mathrm{MH} 3 \mathrm{D}:$ & $\mathrm{C}_{5} \mathrm{H}_{8} \mathrm{O}_{2}$ & 1.37 & 2.56 & 0.88 & 1.05 \\
\cline { 2 - 6 } $\mathrm{C}_{7} \mathrm{H}_{12} \mathrm{O}_{2}$ & $\mathrm{C}_{8} \mathrm{H}_{14} \mathrm{O}_{2}$ & 2.74 & 5.13 & 1.76 & 2.10 \\
\hline Hexadecane: & $\mathrm{C}_{16} \mathrm{H}_{34}$ & 40.23 & 36.41 & 44.37 & 43.76 \\
$\mathrm{C}_{16} \mathrm{H}_{34}$ & & & & & \\
\hline $\mathrm{HXD} 14:$ & $\mathrm{C}_{5} \mathrm{H}_{8}$ & 1.28 & 0.46 & 0.00 & 0.13 \\
$\mathrm{C}_{6} \mathrm{H}_{10}$ & $\mathrm{C}_{7} \mathrm{H}_{12}$ & 1.28 & 0.46 & 0.00 & 0.13 \\
\hline
\end{tabular}

of dimerisation is not considered. The collision kernel in the coagulation term for the free molecular and continuum regimes is described according to Vemury and Pratsinis [33]. Therefore, the coagulation rate is dependent on particle size and temperature. The empirical parameters therein were calibrated based on ethylene diffusion flames [19] using the gas-phase chemistry by Blanquart et al. [34]. More details on the model can be found in [19].

\section{Results and discussion}

Figure 2 presents the measured and modelled spatial distribution of the soot volume fraction, $f_{v}$, for the case of a neat diesel flame (D100) from $\mathrm{HAB}=4 \mathrm{~mm}$ to $32 \mathrm{~mm}$. The D100 flame is a sooting flame, and unburnt soot is emitting from the flame tip. The probe volume does not cover the whole flame due to the limited size of the laser sheet. However, the maximum soot volume fraction zone is captured. Both measured and model patterns of the sooting zone indicate a coincidence of the highest soot zone forming 

(6.9 ppm) is only $52 \%$ of the experimentally measured value of $13 \mathrm{ppm}$ ). The sooting propensity of biodiesels and methyl esters was investigated in

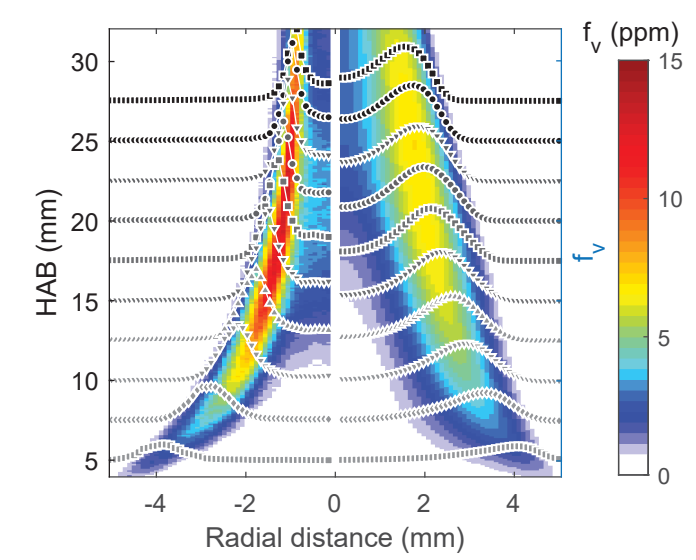

Figure 2: Measured (left) and modelled (right) $f_{v}$ in D100 flame from HAB $=4$ to 32 $\mathrm{mm}$. Dotted lines show profiles plotted in steps of $5 \mathrm{~mm}$ HAB.

187

region on the inside of the high temperature zone. The model results show a significantly broader distribution compared to the very thin measured soot production zone.

The inception of soot takes place around the intersection between the fuel and air streams at the burner exit, and the maximum soot volume fraction $f_{v, m}$ appears near the reaction zone at the interface of fuel and air, at between 20 and $25 \mathrm{~mm} \mathrm{HAB} \mathrm{(22.0} \mathrm{mm}$ for measured data and $24.5 \mathrm{~mm}$ for model). The predicted maximum soot volume fraction obtained by the simulation

six series of cases (from CP to MM). The tested cases are noted by the two initial letters of the biofuel and the percentage by mass used in the mixture, e.g. CP20 refers to $20 \%$ by mass in carotino red palm oil biodiesel. The results of all tested cases are shown in Fig. 3. The tested biodiesel cases denoted as CP, RB, DU and GO are shown in the four rows. Both measured 
and simulated $f_{v}$ map of each case are shown in each sub-figure. However, due to the lack of validated reaction mechanism, the flames of ML and MM are not modelled, hence only the measured data of the two methyl esters are shown in Fig. 3 (bottom line of sub-figures). For cases with blending ratio $r_{b} \leq 60 \%$ of biodiesel, the visible flame height is not well-defined, as the unburnt soot emits from the flame tips. In contrast, when $r_{b} \geq 80 \%$, the soot no longer emits from the flame tip, which means all soot is oxidised across the flame.

Measurements show a dramatic drop in the observable height where soot is detected, $r_{b}$, from $60 \%$ to $80 \%$. However, this behaviour is not reproduced well by the simulation. For all four cases of biodiesel blends, when $r_{b} \geq 80 \%$, the calculated maximum heights where soot is found are significantly larger than experimental measurements. The behaviour of the sooting region height can be explained using the variation in the stoichiometric mixture fraction $Z_{s t}$ of the diffusion flames, which can be evaluated by $Z_{s t}=\left(Y_{o x, 0} / S\right) /\left(Y_{f u, 0}+Y_{o x, 0} / S\right)$, where $Y_{o x, 0}$ is the mass fraction of $\mathrm{O}_{2}$ in the oxidiser side and $Y_{f u, 0}$ is the mass fraction of fuel in the fuel stream, $S$ is the stoichiometric mass ratio of $\mathrm{O}_{2}$ to fuel. The calculated $Z_{s t}$ for D100 is $0.0155,0.0180 \pm 0.0005$ for all neat biodiesel, 0.0191 for ML and 0.0186 for MM. Higher $Z_{s t}$ suggests a location of the isosurface towards the fuel side, thus rendering the flame and sooting zone thinner. Values for the maximum soot volume fraction $f_{v, m}$ in each flame series are shown in Fig. 4. Both experiment and simulation show a decrease in $f_{v, m}$ with increasing $r_{b}$. Pure diesel yields the highest $f_{v m}$ due to the presence of aromatic hydrocarbons and zero bound oxygen. In all neat and blended cases, two biofuels CP and 


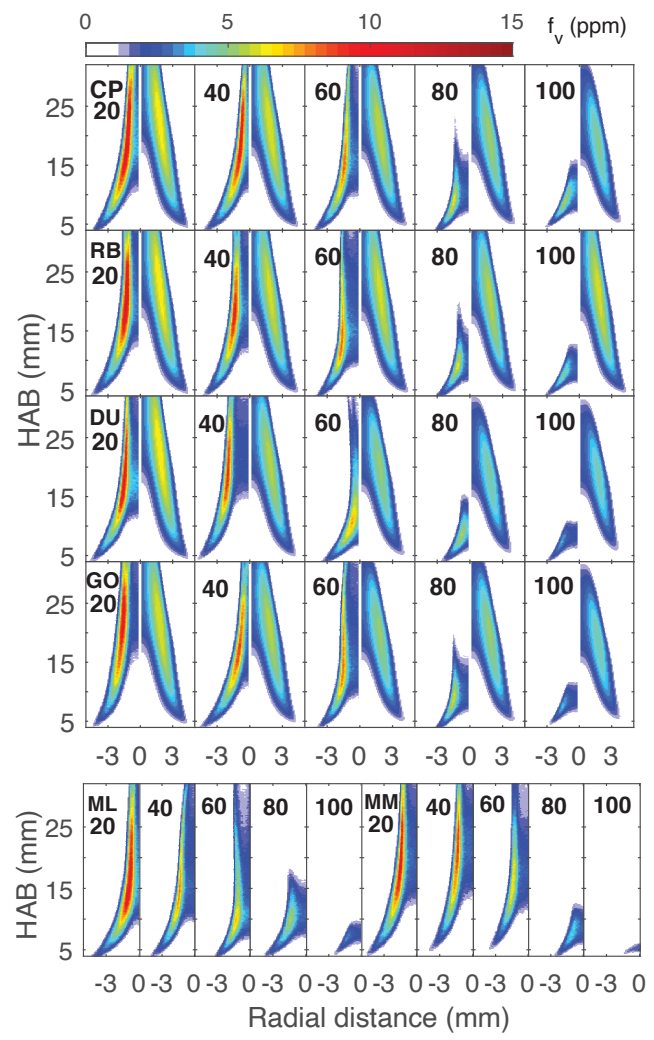

Figure 3: Upper: measured and modelled $f_{v}$ for each test case. Measurements (left panels), models (right panels) for each fuel and $\%$ by mass addition. Bottom: measured $f_{v}$ for ML and MM cases.

$\mathrm{RB}$, which are derived from plant oil with higher unsaturation degree (UD) yield higher $f_{v, m}$ than DU and GO. Considering that the oxygen mass fraction of the tested biodiesels are almost identical, the result indicates that the UD is a key factor for soot yield, as observed in [17] for other fuels. This finding is in consistency with Das et al.'s study [11]. Not surprisingly, ML and MM produce lowest $f_{v, m}$, in which the values in ML100 and MM100 are $24.4 \%$ and $14.2 \%$ of D100, owing to the fact that they are fully saturated and with higher oxygen mass fraction as indicated in Table 1. Although 


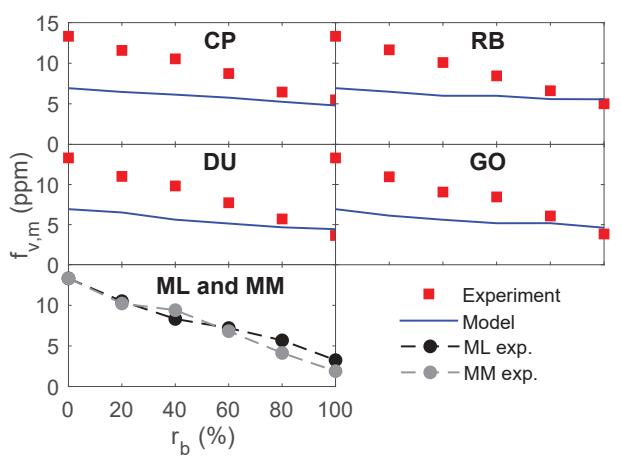

Figure 4: Measured and modelled $f_{v, m}$ as a function of biodiesel volume fraction.

the model does predict correctly a decrease in $f_{v, m}$ with $r_{b}$ for all biodiesels, the rate of change is not well predicted. However, the very low maximum soot values for all neat biodiesels are very well predicted. A database of measured and modelled $f_{v}$ distributions (data-readable TIFF figure) for all tested cases is presented as supplementary data. Previous studies show that the biodiesels reduce soot formation by both the displacement of aromatic species with long-chained esters, as well as the presence of oxygen $[10,35]$. The maximum soot volume fraction, $f_{v, m}$, obtained, per unit carbon for the tested neat fuel cases is shown in Fig. 5. The value obtained per unit carbon for diesel is about 2.5 times that of biodiesels and 5 times that of pure methyl esters.

A reasonable, if imperfect, measure of the total soot formation propensity can be constructed using an integrated total mean soot volume fraction $\bar{f}_{v, \text { int }}$ in the flames over the detectable region from $\mathrm{HAB}=0$ to $32 \mathrm{~mm}$, so that $\bar{f}_{v, \text { int }}=\left(\frac{1}{\pi R^{2} H}\right) \int_{0}^{H} \int_{0}^{R} 2 \pi r f_{v}(r) \mathrm{d} r \mathrm{~d} z$, where $R$ is the radius of the fuel tube and $H=32 \mathrm{~mm}$. The measured values of $\bar{f}_{v, \text { int }}$ for diesel, CP, RB, DU and GO biodiesels are 2.18, 0.60, 0.44, 0.32 and 0.33 ppm respectively, 


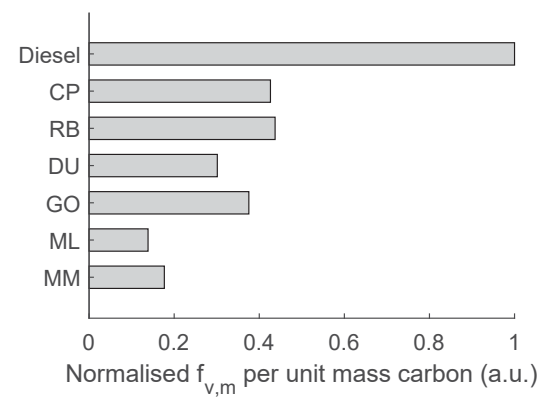

Figure 5: Normalised maximum soot volume fraction $f_{v, m}$ per unit of carbon consumed. For the neat biodiesel cases, the predicted values of $\bar{f}_{v}$ are commensurate

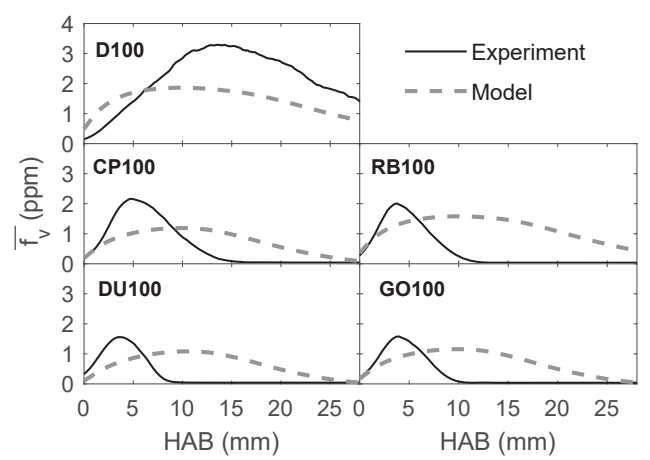

Figure 6: Measured and modelled area weighted mean soot volume fraction $\frac{1}{\pi R^{2}} \int_{0}^{R} 2 \pi r f_{v}(r) \mathrm{d} r$ in unblended cases. $R$ is the radius of the fuel tube.

248

while the modelled values are $1.47,0.75,0.87,0.65$ and $0.70 \mathrm{ppm}$, a significant discrepancy, which is larger for the biodiesel cases. An area-based mean soot volume fraction can be defined as $\bar{f}_{v}=\left(\frac{1}{\pi R^{2} H}\right) \int_{0}^{R} 2 \pi r f_{v}(r) \mathrm{d} r$ for each area, to identify the regions of higher discrepancy. The mean soot volume fractions as a function of $\mathrm{HAB} \bar{f}_{v}$ of all neat cases are plotted in Fig. 6 .

with the measurements, but the extent of the measurements is confined to a much narrower region, as expected from 3. The SEM measured particle size and corresponding lognormal fits for all neat cases are shown in Fig. 


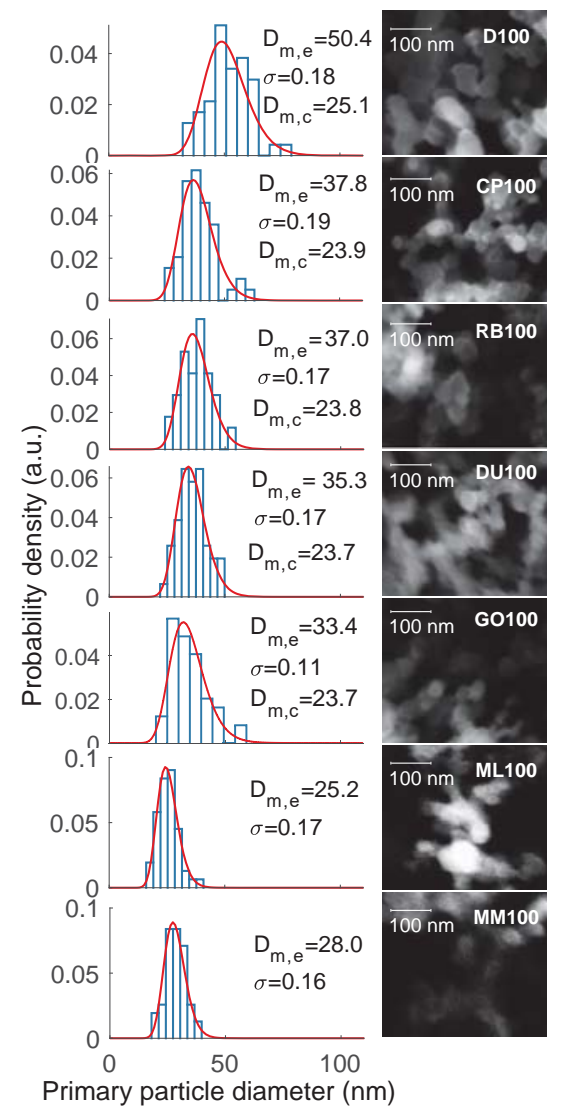

Figure 7: SEM images and corresponding particle size distribution for tested neat fuel cases. Best lognormal fit of the measured diameter distribution shown as red solid line. Best fit values of geometric mean diameter $D_{m, e}$ and distribution width $\sigma$ are shown in the histogram for each case. The calculated mean particle diameter $D_{m, c}$ using the model described in Section 3 is also listed in the figure. 
7. The primary particle size was modelled as a lognormal distribution, with a best fit geometric mean diameter $D_{m, e}$, and distribution width $\sigma$, as obtained from experiments, and shown in the histograms of tested cases. The results indicate that the cases with higher $f_{v}$ also yield larger $D_{m, e}$. The calculated values obtained, $D_{m, c}$, are however, somewhat smaller than measured values. Experimentally measured number densities are estimated as $N_{p}=6 f_{v} / \pi D_{m, e}^{3}$. The results show that not only do biofuels produce smaller particle sizes, but also a smaller number of particulates compared to diesel. For example, the $D_{m, e}$ derived mean particle volume in CP100 case is about $41 \%$ of D100 case, and the estimated $\bar{f}_{v}$ are around $28 \%$ of D100. The estimated number density of soot particles in the case of biodiesels is $30 \%$ to $35 \%$ lower than that of D100, showing that the biofuels not only produce smaller particle sizes, but also fewer particulates compared to diesel.

Among biofuels, the two most unsaturated fuels ( $\mathrm{CP}$ and $\mathrm{RB}$ ) produce larger sizes and number densities of soot particles compared to the two less saturated biofuels (DU and GO) and the two methyl esters (ML and MM). This results from the fact that unsaturated bonds increase the concentration of both soot inception and growth species such as benzene $\mathrm{C}_{6} \mathrm{H}_{6}$ and acetylene $\mathrm{C}_{2} \mathrm{H}_{2}$, which are believed to be the main soot surface growth species according to the HACA mechanism [31]. Similar conclusions were also drawn in [7], in which the fuel was diluted using $\mathrm{N}_{2}$.

As a whole, the soot model can effectively capture the reduction of soot formation by adding biodiesel fuels. However, several discrepancies between simulations and measurements arise, namely: for the pure diesel case, soot value predictions are lower than those measured, and the soot also disappears 
later than predicted. For biodiesels, the concentrations are lower and more distributed, and the average primary particle size is smaller. The differences can be attributed to the following reasons.

First, by approximating the ratio of carbon/hydrogen/oxygen, bond satura302tion and heating values, we assumed input compositions of the diesel and biodiesel fuels in the simulations (Tables 2 and 3). However, these are still simplifications compared to the hundreds of hydrocarbons present. Second, the chemical kinetic model [18] employed in this simulation is semi-detailed for pyrolysis and combustion of the main substances of diesel and biodiesel fuels.

However, many elementary chemical reactions are condensed into model reactions, and the concentrations of the precursor species (PAHs, OH, $\mathrm{C}_{2} \mathrm{H}_{2}$ ) used in soot modelling. Lastly, soot modelling relies on empirical parameters from the gas-phase chemistry by Blanquart et al. [34], which were in turn calibrated based the measured soot morphology (average primary particle size) in ethylene diffusion flames [19], rather than the present biofuel or liquid fuel flames. The soot model applied in this research proves to be reasonable in dealing with sooting flames with different fuels, but is likely to be more accurate by adjusting based on morphological parameters in the diesel and biodiesel fuels individually. However, the precondition is that we have sufficient knowledge to confirm the uncertainty of the chemical mechanism or find more accurate but efficient chemical kinetics, because the community have consensus that empirical parameters of soot models are dependent on the flame type, fuel and the chemical mechanisms employed. 
20

\section{Conclusions}

Soot volume fractions in undiluted, fully pre-vapourised, co-flow diffusion diffusion flames fuelled with four real biodiesels, two methyl esters, and their blends with petroleum diesel were measured using LII/extinction and modelled using diffusion flame models including population balance and soot kinetics. The maximum soot volume fraction $\left(f_{v, m}\right)$ measured using neat biodiesels cases is between $24.4 \%-41.2 \%$ of the corresponding values in a pure diesel flame (D100). SEM image analysis of samples shows that the biodiesel combustion in co-flow diffusion flames produces smaller particle sizes compared to the D100 case.

A comparison between soot production by biodiesel and methyl esters shows that the unsaturation degree correlates positively with the sooting propensity of fuels. Simulations have employed a population balance-based soot model and a semi-detailed chemical mechanism. The results show that the model can capture the reduction of soot formation by addition of biodiesels, but not necessarily the rate of decrease with blending. Further work is required to resolve discrepancies between numerical and experimental results, especially in the case of D100.

\section{Acknowledgements} supported by the Newton Advanced Fellowship of the Royal Society (NA160115). Anxiong Liu gratefully acknowledges the financial support of the Chinese Scholarship Council (CSC) and the EPSRC grant No. EP/S012559/1. 


\section{References}

[1] J. V. Gerpen. Biodiesel processing and production. Fuel Processing Technology, 86(10):1097 - 1107, 2005. Biodiesel Processing and Production.

[2] M. R. Kholghy, J. Weingarten, and M. J. Thomson. A study of the effects of the ester moiety on soot formation and species concentrations in a laminar coflow diffusion flame of a surrogate for B100 biodiesel. Proceedings of the Combustion Institute, 35(1):905-912, 2015.

[3] M. K. Tran, D. Dunn-Rankin, and T. K. Pham. Characterizing sooting propensity in biofuel-diesel flames. Combustion and Flame, 159(6):21812191, 2012.

[4] S. K. Hoekman, A. Broch, C. Robbins, E. Ceniceros, and M. Natarajan. Review of biodiesel composition, properties, and specifications. Renewable and Sustainable Energy Reviews, 16(1):143 - 169, 2012.

[5] J. Abboud, J. Schobing, G. Legros, J. Bonnety, V. Tschamber, A. Brillard, G. Leyssens, V. Lauga, E. E. Iojoiu, and P. D. Costa. Impacts of oxygenated compounds concentration on sooting propensities and soot oxidative reactivity: Application to Diesel and Biodiesel surrogates. Fuel, 193:241-253, 2017.

[6] Z. Gao, L. Zhu, X. Zou, C. Liu, B. Tian, and Z. Huang. Soot reduction effects of dibutyl ether (DBE) addition to a biodiesel surrogate in laminar coflow diffusion flames. Proceedings of the Combustion Institute, 37 (1):1265-1272, 2019. 
[7] M. R. Kholghy, J. Weingarten, A. D. Sediako, J. Barba, M. Lapuerta, and M. J. Thomson. Structural effects of biodiesel on soot formation in a laminar coflow diffusion flame. Proceedings of the Combustion Institute, 36(1):1321-1328, 2017.

[8] W. Merchan-Merchan, S. McCollam, and J. F. C. Pugliese. Soot formation in diffusion oxygen-enhanced biodiesel flames. Fuel, 156:129-141, 2015.

[9] W. Merchan-Merchan, A. Abdihamzehkolaei, and D. A. MerchanBreuer. Formation and evolution of carbon particles in coflow diffusion air flames of vaporized biodiesel, diesel and biodiesel-diesel blends. Fuel, 226(November 2017):263-277, 2018.

[10] R. Lemaire, S. Bejaoui, and E. Therssen. Study of soot formation during the combustion of Diesel, rapeseed methyl ester and their surrogates in turbulent spray flames. Fuel, 107:147-161, 2013.

[11] Dhrubajyoti D. Das, Charles S. McEnally, and Lisa D. Pfefferle. Sooting tendencies of unsaturated esters in nonpremixed flames. Combustion and Flame, 162(4):1489-1497, 2015.

[12] C. T. Chong, B. Tian, Han N-J, L. Fan, S. Ni, K. Wong, and S. Hochgreb. Quantification of carbon particulates produced under open liquid pool and prevaporised flame conditions: Waste cooking oil biodiesel and diesel blends. Fuel, 270, 2020. doi: 10.1016/j.fuel.2020. 117469. 
[13] C. T. Chong and S. Hochgreb. Spray combustion characteristics of palm biodiesel. Combustion Science and Technology, 184(7-8):10931107, 2012.

[14] M. Matti Maricq. Physical and chemical comparison of soot in hydrocarbon and biodiesel fuel diffusion flames: A study of model and commercial fuels. Combustion and Flame, 158(1):105-116, 2011.

[15] B. Tian, Y. Gao, C. Zhang, and S. Hochgreb. Soot measurement by combining continuous wave multipass extinction and laser-induced incandescence in diluted methane flames. Combustion and Flame, 192: 224-237, 2018.

[16] B. Tian, Y. Gao, S. Balusamy, and S. Hochgreb. High Spatial Resolution Laser Cavity Extinction and Laser Induced Incandescence in Low Soot Producing Flames. Applied Physics B, 120(3):469-487, 2015.

[17] B. Tian, C.T. Chong, L. Fan, J.-H. Ng, C. Zhang, and S. Hochgreb. Soot volume fraction measurements over laminar pool flames of biofuels, diesel and blends. Proceedings of the Combustion Institute, 37(1):877884, 2018.

[18] E. Ranzi, A. Frassoldati, R. Grana, A. Cuoci, T. Faravelli, A. P. Kelley, and C. K. Law. Hierarchical and comparative kinetic modeling of laminar flame speeds of hydrocarbon and oxygenated fuels. Progress in Energy and Combustion Science, 38(4):468-501, 2012.

[19] Anxiong Liu and Stelios Rigopoulos. A conservative method for numer- 
ical solution of the population balance equation, and application to soot formation. Combustion and Flame, 205:506-521, 2019.

[20] J. Yon, R. Lemaire, E. Therssen, P. Desgroux, A. Coppalle, and K. F. Ren. Examination of wavelength dependent soot optical properties of diesel and diesel/rapeseed methyl ester mixture by extinction spectra analysis and LII measurements. Applied Physics B, 104(2):253-271, 2011.

[21] P. K. Sahoo, L. M. Das, M. K.G. Babu, P. Arora, V. P. Singh, N. R. Kumar, and T. S. Varyani. Comparative evaluation of performance and emission characteristics of jatropha, karanja and polanga based biodiesel as fuel in a tractor engine. Fuel, 88(9):1698-1707, 2009.

[22] M. Chhabra, A. Sharma, and G. Dwivedi. Performance evaluation of diesel engine using rice bran biodiesel. Egyptian Journal of Petroleum, 26(2):511-518, 2017.

[23] A. Probudha Hasan, A. Wakil, and A. Kafy. Prospect of rice bran for biodiesel production in Bangladesh. Procedia Engineering, 90(December 2014):746-752, 2014.

[24] NIST. Chemistry webbook, srd 69, dodecanoic acid, methyl ester. https://webbook.nist.gov/cgi/cbook.cgi?ID=111-82-0, 2018. Accessed: 2019-03-10.

[25] NIST. Chemistry webbook, srd 69, methyl tetradecanoate n.d. https: //webbook.nist. gov/cgi/cbook. cgi? ID=C124107\&Mask=4, 2018. Accessed: 2019-03-10. 
[26] Y. Ying and D. Liu. Effects of butanol isomers additions on soot nanostructure and reactivity in normal and inverse ethylene diffusion flames. Fuel, 205:109-129, 2017.

[27] J. Duan, Y. Ying, and D. Liu. Novel nanoscale control on soot formation by local CO2 micro-injection in ethylene inverse diffusion flames. Energy, 179:697-708, 2019.

[28] A. Frassoldati, A. Cuoci, A. Stagni, T. Faravelli, and E. Ranzi. Skeletal kinetic mechanism for diesel combustion. Combustion Theory and Modelling, 21(1):79-92, 2017.

[29] Y. Ra and R. D. Reitz. A combustion model for IC engine combustion simulations with multi-component fuels. Combustion and Flame, 158 (1):69-90, 2011.

[30] A. Li, L. Zhu, Y. Mao, J. Zhai, D. Han, X. Lu, and Z. Huang. Surrogate formulation methodology for biodiesel based on chemical deconstruction in consideration of molecular structure and engine combustion factors. Combustion and Flame, 199:152-167, 2019.

[31] Michael Frenklach. Reaction mechanism of soot formation in flames. Physical Chemistry Chemical Physics, 4(11):2028-2037, 2002.

[32] H. Bockhorn, A. D'Anna, A. F. Sarofi, and H. Wang. A joint volumesurface-hydrogen multi-variate model for soot formation. In Combustion Generated Fine Carbonaceous Particles, pages 437-463. KIT Scientifi Publishing, Karlsruhe, 2009. 
[33] Srinivas Vemury and Sotiris E. Pratsinis. Self-preserving size distributions of agglomerates. Journal of Aerosol Science, 26(2):175-185, 1995.

[34] G. Blanquart, P. Pepiot-Desjardins, and H. Pitsch. Chemical mechanism for high temperature combustion of engine relevant fuels with emphasis on soot precursors. Combustion and Flame, 156(1):588-607, 2009.

[35] P. Pepiot-Desjardins, H. Pitsch, R. Malhotra, S. R. Kirby, and A. L. Boehman. Structural group analysis for soot reduction tendency of oxygenated fuels. Combustion and Flame, 154(1-2):191-205, 2008. 